\title{
Optimization and Numerical Simulation of Outlet of Twin Screw Extruder
}

\author{
Yuan Zhang, Xiaohan Jiang, Huaping Fan and Xihan Li \\ School of Mechanical and Power Engineering,Harbin University of Science and Technology, 150080Harbin ,China
}

\begin{abstract}
In view of the unreasonable design of non-intermeshing counter-rotating twin screw extruder die, the problem of productivity reduction was discussed. Firstly, the mathematical model of extruder productivity was established. The extruder die model was improved. Secondly, the force analysis of twin screw extruder physical model was carried out. Meanwhile, A combination of mechanical analysis and numerical simulation was adopted. The velocity field, pressure field and viscosity field were calculated by Mini-Element interpolation method, linear interpolation method and Picard iterative convergence method respectively. The influence of die model on the quantity of each field before and after improvement was analyzed. The results show that the improved model had increased the rheological parameters of the flow field, the leakage and reverse flow decreased. Through post-processing calculation, the productivity of the third dies extruder was $10 \%$ higher than before. The research results provide a theoretical basis for the design and optimization of die model of non intermeshing counter-rotating twin screw extruder.
\end{abstract}

\section{Introduction}

At present, the extrusion processing as an important means of transport to work $^{[1]}$, screw extruder is widely used in polymer, food and medicine ${ }^{[2-6]}$, while in the traditional Chinese medicine pill making machine, its sliver quality and efficiency directly affects the quality and output rate of the pill.If the model design or the selection of the screw extruder die is not reasonable, not only will the reverse flow and leakage flow increase, but also the efficiency will be reduced. The method of numerical simulation was used to simulate the internal flow field of double screw by Many scholars ${ }^{[7,8]}$. However, the influence of different die models on the flow field in twin screw extruder is not considered in these study.

In order to improve the efficiency of extrusion of the extruder, the die model was optimized with the ANASYS $^{[9]}$ POLYFLOW software as a platform to polymer rheology as the foundation, by means of computer simulation analysis, the influence of the model before and after optimization on rheological parameters of extruder flow field was studied, and the flow characteristics of non Newtonian viscous polymer in screw rod under isothermal condition were analyzed. The simulation results are verified by experiments. It is of great significance to optimize the die model of non intermeshing twin-screw extruder.

\section{Numerical model of extruder}

\subsection{Mathematical model}

In the process of extrusion, the water content and the temperature of the material change constantly, and the viscosity changes. The material belongs to the rheological body. In order to simplify the calculation, the following assumptions are made:

(1) The interior of the runner is filled with material;

(2) The fluid is a steady flow with time independent;

(3)The temperature in the flow field remains constant;

(4) flow is turbulent flow, and $\mathrm{Re}$ is between $8000 \sim 12000$;

(5) it is assumed that the fluid is incompressible;

(6) the wall of runner is free of sliding;

(7) because of the large viscosity of the fluid, the bulk forces such as gravity and inertia are neglected.

Based on the above hypothesis, in the Cartesian coordinate system, the continuity equation is:

$$
\frac{\partial v_{x}}{\partial x}+\frac{\partial v_{y}}{\partial y}+\frac{\partial v_{z}}{\partial z}=0
$$

Equation of motion is:

$$
-\frac{\partial P}{\partial x}+\left(\frac{\partial \tau_{x x}}{\partial x}+\frac{\partial \tau_{y x}}{\partial y}+\frac{\partial \tau_{z x}}{\partial z}\right)=\rho \frac{\partial v_{x}}{\partial t}
$$




$$
\begin{aligned}
& -\frac{\partial P}{\partial y}+\left(\frac{\partial \tau_{x y}}{\partial x}+\frac{\partial \tau_{y y}}{\partial y}+\frac{\partial \tau_{z y}}{\partial z}\right)=\rho \frac{\partial v_{y}}{\partial t} \\
& -\frac{\partial P}{\partial z}+\left(\frac{\partial \tau_{x z}}{\partial x}+\frac{\partial \tau_{y z}}{\partial y}+\frac{\partial \tau_{z z}}{\partial z}\right)=\rho \frac{\partial v_{z}}{\partial t}
\end{aligned}
$$

Considering that the material belongs to food processing, the shear rate is not too high, and the constitutive equation is simplified power law model:

$$
\eta=\zeta\left(\frac{1}{2} \dot{I}_{2}\right)^{\frac{n-1}{2}}
$$

The volumetric flow rate formula of twin screw extruder is

$$
\begin{aligned}
& Q_{\text {总 }}=2 Q=i \pi^{2} d^{2} n h \cos \theta \sin \theta- \\
& \frac{\Delta P}{6 \eta L_{1}}\left[\left(i h^{3} d \pi \sin ^{2} \theta+\pi^{2} q d^{2} \delta^{3} \tan \theta / e\right)\right.
\end{aligned}
$$

$i$ - screw head number $d$-screw outer diameter

$$
\begin{array}{lll}
n \text { - screw speed } & h \text { - groove depth } & \theta \text { - helix angle } \\
\eta \text { - viscosity } & e \text {-screw width } & L \text { - pitch }
\end{array}
$$

$d_{1}$ - screw diameter $\quad L_{1}$ - measuring section length

$\Delta P$-Pressure drop at both ends of metering section

$q$ - meshing coefficient, which indicates the influence of the meshing area on the material flow due to the engagement of two screws

\subsection{Physical model}

Through the experiment of dual-mode extrusion machine efficiency is not very high, the extrusion speed is slow, so the die was optimized, the optimized die model eliminates the elbow, will shorten the length of extrusion, and on the basis of the original increase in a die model, as shown in figure 1 .

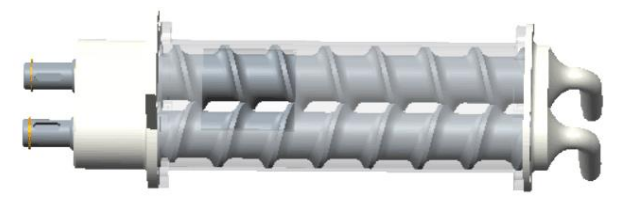

(a) two dies

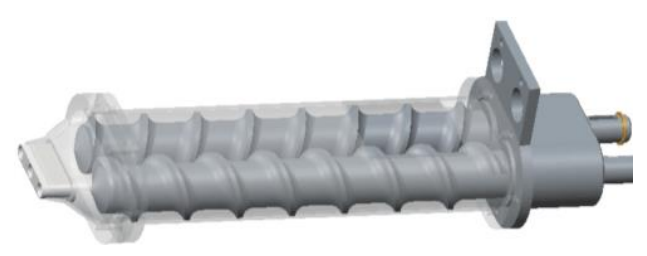

(b) three dies

Figure 1. A model for the twin screw extruder

The main performance parameters of twin-screw extruder include screw diameter, center distance, pitch and so on, as shown in figure 2 :

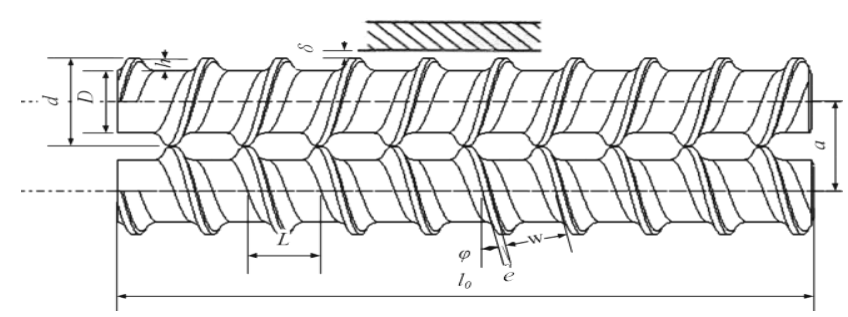

$D$ - screw internal diameter; $\delta$-clearance; $a$ - center distance; $\varphi$-thread lift angle; $w$ - spiral groove width; $l_{0}$ - screw length

Figure 2. Twin-screw extruder structure parameters

\section{Simulation analysis of flow field in extrusion process}

\subsection{Material parameter}

Since the ingredients of the powder are complex, flour is used as a substitute. By referring to the relevant literature $^{[10]}$, the parameters of the flour melt material were obtained. The consistency coefficient was $25680 \mathrm{~Pa}$. $\mathrm{Sn}$, the flow index was 1.42 and the density was $850 \mathrm{~kg} / \mathrm{m}^{3}$.

\section{2 boundary condition}

In the flow field simulation of the extruder runner, the inlet volume flow rate and outlet pressure are given, and the material has no slippage with the inner wall of the cylinder and the surface of the screw:

(1) Define the entrance boundary of computational domain by volume flow rate, $V=6.42 \times 10^{-5} \mathrm{~m}^{3} / \mathrm{min}$;

(2)The exit boundary is defined by the pressure value, $P=6.25 \times 10^{6} \mathrm{~Pa}$

(3) Set the speed boundary at the head of the twin screw. In the direction of extrusion, the speed of the left screw is $-20 \mathrm{r} / \mathrm{min}$, the direction is clockwise, the speed of the right screw is $20 \mathrm{r} / \mathrm{min}$, and the direction of the screw is counterclockwise.

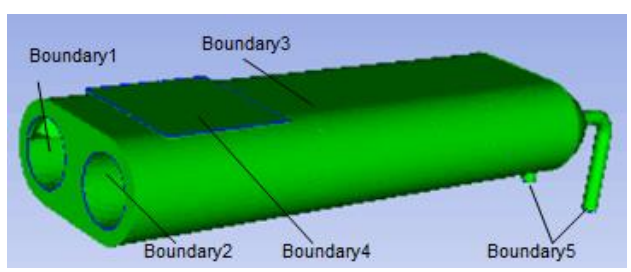

(a) two dies

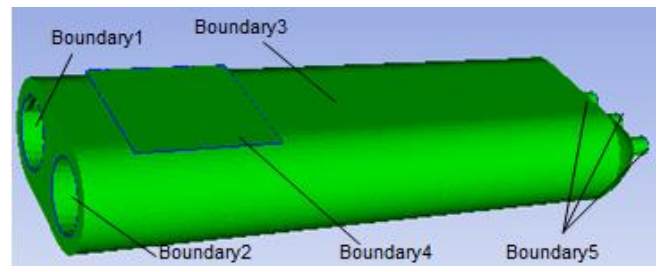

(b) three dies

Figure 3. boundary names

Figure 3 is the runner part boundary name, Boundary4 is runner inlet, Boundary5 is runner outlet, 
Boundary3 is runner and cylinder contact surface, Boundary1 and Boundary2 are runner and left and right screw contact surface. Table 1 is the channel flow boundary condition.

Table 1. Flow channel boundary condition setting

\begin{tabular}{|c|c|}
\hline Boundary position & Flow boundary condition \\
\hline Boundary1 & Descartes speed input boundary \\
\hline Boundary2 & Descartes speed input boundary \\
\hline Boundary3 & no slip at wall \\
\hline Boundary4 & Volume flow rate \\
\hline Boundary5 & Natural flow like fixed outlet pressure \\
\hline
\end{tabular}

3.3 Analysis of rheological parameters of materials during steady compression and extension

FEM method was used to model nonlinear control coupling equation of power-law solution in the mesh module of the screw and the runner model grid and the grid overlap, set the parameters in polydata, in order to improve the accuracy of the calculation, calculation of single element velocity field using Mini-Element interpolation method to calculate the pressure field by using the linear interpolation method, calculation of viscosity using Picard iterative method, using algebraic equation group implicit Euler method for solving the discrete after. Through the post-processing module CFD-POST, the results of each rheological parameter were analyzed, and the flow velocity, pressure, viscosity parameter nephogram and the change curve of parameters with the axial distance were obtained.

\subsubsection{Velocity field distribution}

After using CFD-POST to visualize the results, the velocity vector distribution of the flow channel was shown in Figure 4 and the contour map of velocity distribution at the die mouth are obtained.

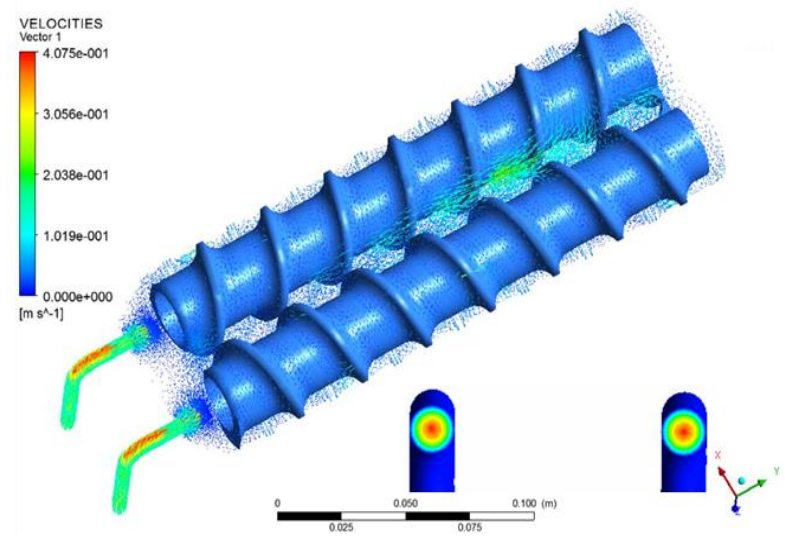

(a) two dies

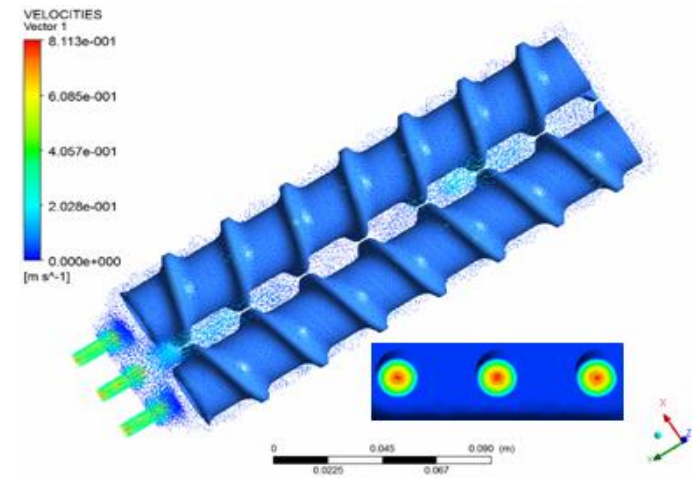

(b) three dies
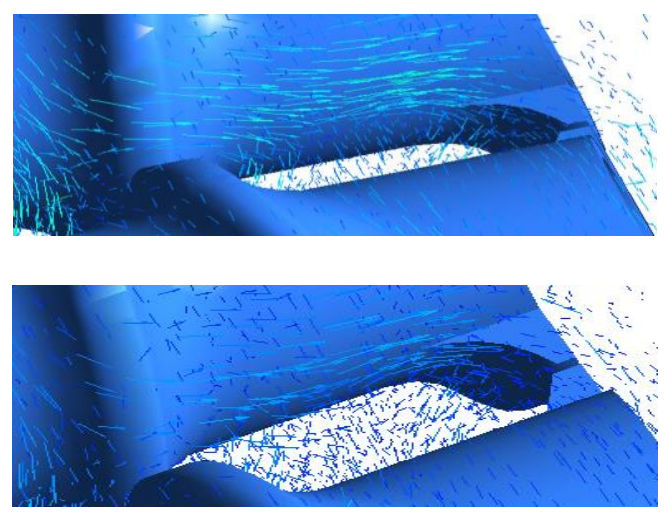

(c) Local amplification of the screw tip near the entrance Figure 4. Flow velocity vector diagram and die speed contour map

The change trend of the drawing speed showed that maximum speed of the die in the axis, and the trend was from the wall to the axial velocity increasing gradually, a small amount of leakage at the entrance and measurement section. After the measuring section, the materials were gathered to the die, got the material in the metering section average velocity, the velocity of double dies was $0.02579 \mathrm{~m} / \mathrm{s}$, and three dies was $0.06372 \mathrm{~m} / \mathrm{s}$. Showed that the velocity vector images, material appeared counter current phenomenon at the entrance, and two port inverse flow and speed was obviously higher than that of the three dies in the model, as shown in figure 7 (c) shows.

\subsubsection{Pressure field distribution}

Pressure contours showed that both the two and the three dies, the maximum pressure appeared in the die, and from the entrance to the die pressure decreased first and then increased, figure 5 showed the screw top near the entrance area darker, larger pressure. From the color, it can be seen that the pressure drop between the measuring section and the die mouth was different. 


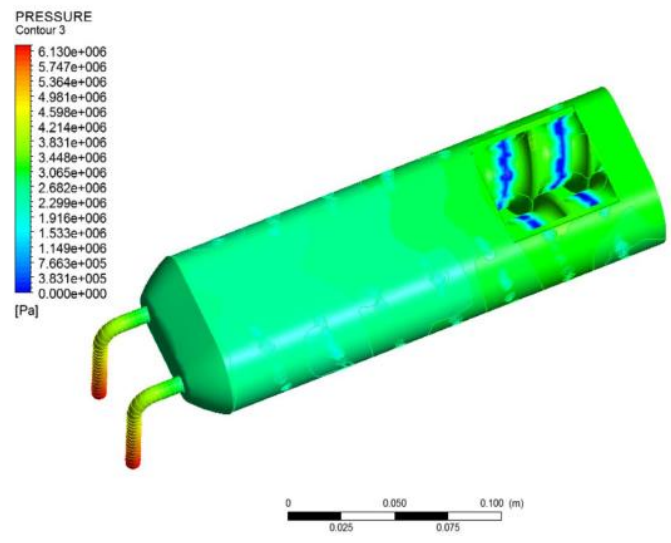

(a) two dies

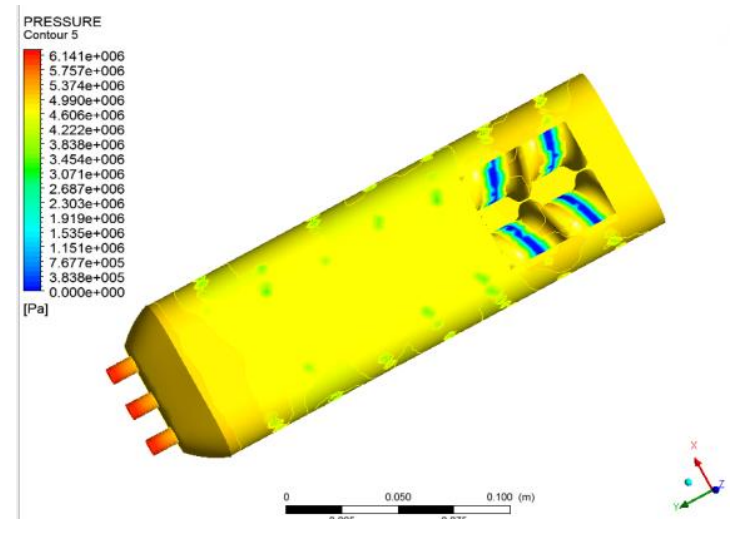

(b) three dies

Figure 5. Pressure distribution diagram of flow channel

Figure 6 was a two dies and the three dies extrusion machine from the metering section to the die pressure trend comparison, the graph showed that the three dies export metering section of the pressure was higher than the double export, but export dual extruder die pressure drop was bigger, its value was $3.175 \mathrm{MPa}$, the three dies to $1 \mathrm{MPa}$, because the double die model had elbow, and the elbow was too long to the exit, the long elbow caused a sharp change in the die pressure.

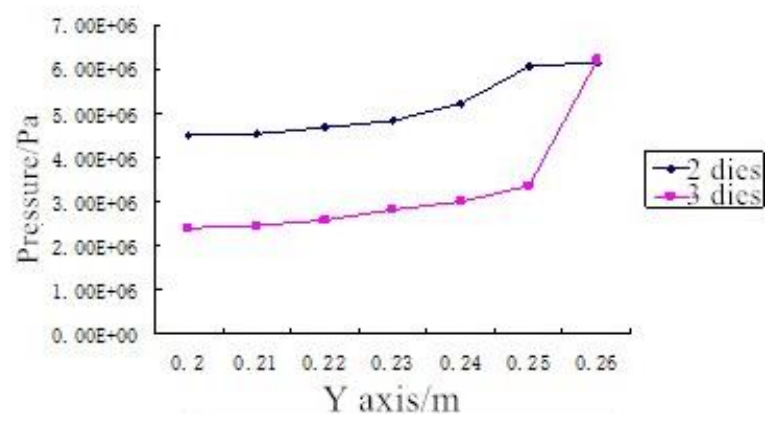

Figure 6.Pressure distribution diagram of flow channel

\subsubsection{Viscosity distribution}

The material viscosity had some influence on the extrusion efficiency. The material chosen for the simulation was an expanding plastic fluid, which had the characteristics of shear thickening, that was, the apparent viscosity of fluid increases with the increase of shear rate. Figure 7 showed the distribution of channel viscosity.

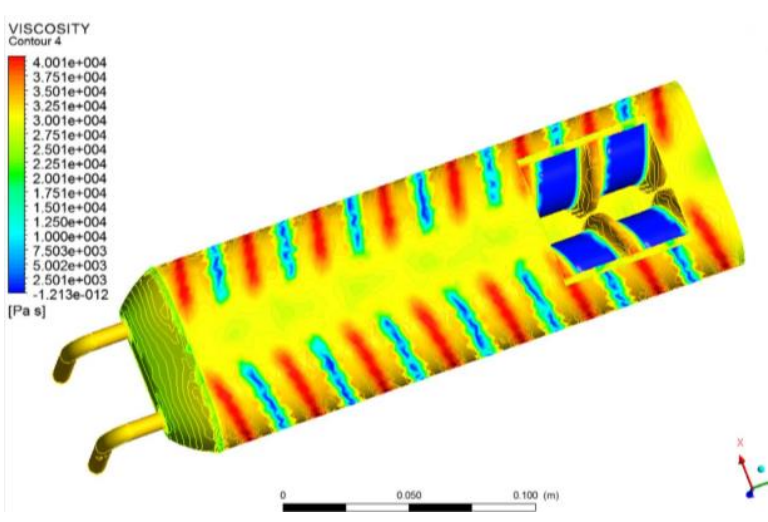

(a) two dies

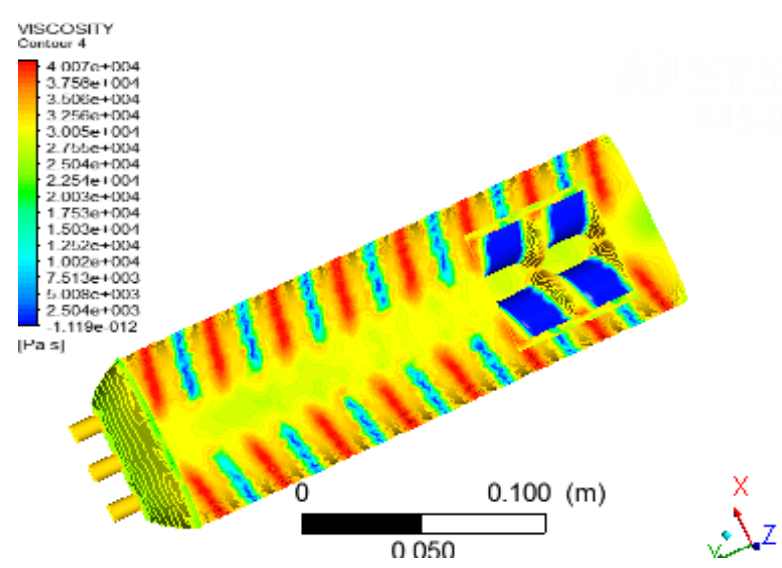

(b) three dies

Figure 7. Viscosity distribution

The viscosity of cloud display, two dies and three dies extrusion runner viscosity reached the maximum at the edge, the maximum values were $40010 \mathrm{~Pa} \cdot \mathrm{s}$ and $40070 \mathrm{~Pa} \cdot \mathrm{s}$, when the die size was constant, the viscosity increased with the increase of the pressure, so the viscosity change flow rate has little effect, but the die diameter is small and it is not directly affected by the screw, the greater the viscosity, the retarding effect of the material will be stronger, as the die length, roughness, elbow caused by the loss of the process and local losses will increase. After optimization, the elbow part of the double dies orifice was removed and the straight part length of the dies was shortened, the blocking effect of the three dies was far lower than the export by two.

\subsubsection{Comparison of flow field calculation results with actual volumetric flow rate}

The above analysis results and the numerical formula (6) was calculated, respectively, and the positive flow, reverse flow, leakage current and volume flow rate of twin-screw extruder with different die numbers were obtained, as shown in table 2.

After calculation, the volume flow rate before and after optimization were $15.912 \mathrm{~kg} / \mathrm{h}$ and $17.442 \mathrm{~kg} / \mathrm{h}$, the improved model of the reverse flow in the three dies was reduced by $28 \%$, the leakage flow is reduced by $28 \%$, volume flow rate increased by $10 \%$. 
Table2.Productivity comparison of twin screw extruder with different dies

\begin{tabular}{|c|c|c|c|c|}
\hline $\begin{array}{c}\text { Die } \\
\text { number }\end{array}$ & $\begin{array}{c}\text { Positive } \\
\text { flow } \\
\left(\mathrm{m}^{3} / \mathrm{s}\right)\end{array}$ & $\begin{array}{c}\text { Against } \\
\text { the } \\
\text { Current } \\
\left(\mathrm{m}^{3} / \mathrm{s}\right)\end{array}$ & $\begin{array}{c}\text { Leakage } \\
\text { current } \\
\left(\mathrm{m}^{3} / \mathrm{s}\right)\end{array}$ & $\begin{array}{c}\text { Volume } \\
\text { flow rate } \\
\left(\mathrm{m}^{3} / \mathrm{s}\right)\end{array}$ \\
\hline 2 & $7.0 \times 10^{-6}$ & $1.8 \times 10^{-6}$ & $5.7 \times 10^{-9}$ & $5.2 \times 10^{-6}$ \\
\hline 3 & $7.0 \times 10^{-6}$ & $1.29 \times 10^{-6}$ & $4.1 \times 10^{-9}$ & $5.7 \times 10^{-6}$ \\
\hline
\end{tabular}

In order to verify the accuracy of the calculated productivity values, the actual flow rates of different die extruders were measured several times at different time, as shown in table 3 , from the measurement results can be seen, the volume flow rate calculation is slightly higher than the actual volume flow rate, two dies and export the three dies error is $5.35 \%$ and $5.53 \%$ respectively.The numerical calculation model compared to the actual measured by the existence of local differences in the structure of extruder, extruder and material surface roughness, the material cannot fill machine and other factors will also affect the results, therefore, under ideal conditions, the simulation value will be higher than the measured value, the error was small, the simulation results can reflect the real situation.

Table 3.Measurement of volume flow rate at different time

\begin{tabular}{|c|c|c|c|c|c|c|}
\hline Time $(\mathrm{min})$ & 10 & 20 & 30 & 40 & 50 & 60 \\
\hline $2 \operatorname{dies}\left(10^{-6} \mathrm{~m}^{3} / \mathrm{s}\right)$ & 4.72 & 4.85 & 4.90 & 5.13 & 5.07 & 4.86 \\
\hline $3 \operatorname{dies}\left(10^{-6} \mathrm{~m}^{3} / \mathrm{s}\right)$ & 5.30 & 5.31 & 5.48 & 5.52 & 5.37 & 5.33 \\
\hline
\end{tabular}

\section{Conclusion}

(1) By comparing the two dies and the three dies export extruder numerical simulation results, two dies and export the three dies in the extruder the material in the average speed of metering section were $0.02579 \mathrm{~m} / \mathrm{s}$ and $0.06372 \mathrm{~m} / \mathrm{s}$, and was significantly higher than that of the three dies mode, it showed that the flow velocity at the measuring section is affected by the die resistance when the viscosity of the measuring section is about the same, double mouth length, roughness and bend along the path of energy loss and increase the local energy loss, resulting in slow flow rate. Therefore, the optimized die model can increase material flow rate and speed up extrusion.

(2)Analyzed the impact on the pressure field of different die model, it was found that the pressure of flow channel of three dies was higher than that of double dies, the pressure distribution showed the trend of decreasing first and then increasing. Through actual measurement the error is within $6 \%$, the calculation results showed that the flow field calculation results have reference value. Display the pressure screw top pressure near the entrance area, showed that the resistance caused by the die resistance moves to the top of the screw, so in the design of extruder entrance should consider this factor, it is necessary to prevent the vacuum of the tip of the screw from rotating when it continues to inhale the material at the entrance, resulting in an increase in counter flow. The entrance can be designed at the top of the screw.

(3) Post processing calculation results showed that the three dies after optimization of the extrusion machine to reduce leakage current and counter current, the volume flow rate increased, indicating the die pressure drop impact on the metering section of the pressure drop, the improved die model makes the metering section of the pressure drop decrease, and to reduce reflux and leakage flow. The three dies after optimization of the extrusion machine can not only improve the output, save time, but also can improve the output efficiency of traditional Chinese medicine pill making machine, which laid a theoretical foundation for the production practice.

\section{References}

1. G.D. Zhang, J.P. Lin, Y.H. Ge , X.Y. Hao. Mold-flow equilibrium coefficient correction of polymer extrusion, Journal of Mechanical Engineering,75-80,48(2012)

2. M.Y. Yue, P. Xue, X.D. Song, J. Zhang, M.Y. Jia, Research progress in screw extrusion technology of explosives, China Plastics, 1-7(2015)

3. Z.B. Chen, Q. Xie, J.J. Du, Y. Li, T. Liu, Melting process of PVCwood-plastic single-screw extruder' $s$ melting section, Plastics, 84-89(2015)

4. A.D. Zhao, X.L. Li, G.Y. Zheng, L.Q. Zhang, Preparation of liquid desulfurization rubber by co-rotating twin screw extruder,China Synthetic Rubber Industry, 78-82, 39(2016):

5. T. Yang, J.M. Xin, Q. Xu, H.Y Luo, The research application status of in food industry, Journal of Food Science and Biotechnology, 733-740 (2009)

6. H W Wano Annliration and research progress of twin screw extruder, Cereals and Oils Processing, 131-134(2009)

7. J.F. Shi, Z.G. Huang, W.X. Jiang, M.L. Li, H.J. Zhang, Study on flow field of polylactic acid in the nose transition body of co-rotating twin-screw extruder, Food \& Machinery, 72-75(2017)

8. S.A. Salahudeen, A.R. Rahmat, Design Parameter to Develop Secondary Flow in Twin Screw Extruder, Applied Mechanics and Materials, (2015)

9. G. Wang, X.Z. Zhu, Y. S. Chun, Numerical Simulation of Mixing Performance of Intermeshing Co-Rotating Tri-Screw and Twin-Screw Extruders, Advanced Materials Research, (2012)

10. S.H. Chen, Theoretical and experimental study of NI-MPE in intermeshing co-rotating twin-screw extrusion, Beijing University of Chemical Technology, (2003) 